\title{
Correlation between Maternal Health Literacy and Dietary Self-Efficacy in Pregnant Mothers
}

\section{ART I CLE IN F O}

\section{Article Type}

Descriptive Study

\section{Authors}

Kharrazi S.S. ${ }^{1} M S c$,

Peyman N.*PhD,

Esmaily $\mathrm{H}^{2} P h D$

How to cite this article
Kharrazi S S, Peyman N, Esmaily
H. Correlation between Maternal
Health Literacy and Dietary Self-
Efficacy in Pregnant Mothers. He-
alth Education and Health Prom-
otion. 2018;6(1):9-16.

*"Health Science Research Center" and "Health Education \& Health Promotion Department, Public Health School", Mashhad University of Medical Sciences, Mashhad, Iran

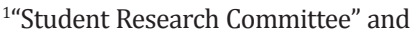
"School of Health", Mashhad University of Medical Sciences, Mashhad, Iran

${ }^{2}$ "Health Science Research Center" and "Biostatistics Department, Public Health School", Mashhad University of Medical Sciences, Mashhad, Iran

\section{Correspondence}

Address: Health Education \& Health Promotion Department, Public Health School, Mashhad University of Medical Sciences, Shahid Fakoori Boulevard, Javan Square, Mashhad, Iran

Phone: +98 (51) 38544643

Fax: +98 (51) 38517505

peymanN@mums.ac.ir

\section{Article History}

Received: September 5, 2017

Accepted: December 15, 2017

ePublished: February 1, 2018

\section{A B S T RA C T}

Aims Health literacy becomes increasingly important in understanding the prenatal perception of risk by pregnant women. Maternal understanding of and perception of risk may have an impact on mothers' willingness to follow antenatal recommendations. This study aimed at investigating correlation between maternal health literacy and dietary self-efficacy in pregnant mothers.

Instruments \& Methods In this cross-sectional descriptive-analytical study, 120 pregnant mothers were selected from health centers in Mashhad city, Iran in 2016. The subjects were selected through multi-stage cluster random sampling method. Data were collected using Maternal Health Literacy and Pregnancy outcomes Questionnaire and Perceived Dietary Self-efficacy Questionnaire. The obtained data were analyzed by SPSS 15 software and using descriptive statistics (mean, standard deviation, and frequency) and analytical statistical tests (independent t-test, ANOVA, Turkey's Post hoc test and Pearson correlation test).

Findings There was a positive and significant correlation between maternal health literacy and dietary self-efficacy $(r=0.29 ; p=0.001)$. Significant relationships were found between maternal health literacy and educational level, incomes, and living place $(\mathrm{p}<0.05)$. But dietary self-efficacy had only a significant relationship with incomes $(\mathrm{p}<0.05)$.

Conclusion There are the significant correlation between maternal health literacy and selfefficacy in pregnant mothers.

Keywords Health Literacy; Pregnant Women; Diet; Self-Efficacy

\section{T A T I O N L I N KS}

[1] Barriers to diabetes management: Patient and ... [2] Assessing the effect of educational program ... [3] The relationship between health literacy ... [4] Health literacy: Concept ... [5] Improvement in maternal health literacy ... [6] Associations between maternal health ... [7] The effect of education on nutrition behavioral ... [8] Investigating adult health literacy in ... [9] Health literacy levels of diabetic patients referred ... [10] Individual determinants of fish consumption ... [11] The relationships between perceived nutritional ... [12] Breaking it down': Patient-clinician communication ... [13] Clinical obstetric outcomes related to continuity ... [14] Brief questions to identify patients with ... [15] Health literacy: A policy challenge for ... [16] Influence of maternal health literacy on healthy ... [17] An evaluation of the validity and reliability ... [18] Health Literacy among Adults in ... [19] Determination of knowledge and health ... [20] Health Literacy and Utilization of ... [21] Health literacy and its relationship with ... [22] Study of health literacy level of women ... [23] Relationship between health literacy ... [24] Health literacy and pregnancy preparedness ... [25] Survey influencing factors on prenatal care in ... [26] Assessing adult health literacy in urban ... [27] Health literacy and the influencing .. [28] Functional health literacy among primary ... [29] Evaluation of health literacy of [30] Performance of a Brazilian population ... [31] Associations between health literacy .. [32] Health literacy and its association ... [33] Preparing for an epidemic of limited ... [34] Effects of health literacy on health ... [35] The prevalence of limited ... [36] The relationship between health literacy and self-efficacy in patients with type II diabetes admitted to Gorgan ... [37] The relationship between health literacy ... [38] The association of health literacy ... [39] The relationship between health ... [40] Health literacy predicts change in physical activity self-efficacy among ... [41] Communicative and critical health literacy and self-care behaviors in patients ... [42] The mechanisms linking health literacy to behavior and health ... [43] Association between maternal health literacy level with pregnancy care and its ... 


\section{Introduction}

Health literacy is the result of an effort to promote social and individual factors, facing health literacy concerns and dimensions, and is recognized as vital to health care outcomes and consequences [1-3]. It is essential to empower for individuals to change their behavior and lifestyle to improve their health and quality of life [4]. Health literacy in pregnant mothers means special awareness and particular social skills to diagnose prenatal risk symptoms, healthy lifestyle and proper nutrition during pregnancy. It influences pregnancy by improving the quality of prenatal care. Mothers with high health literacy tend to have low birth weight infants, early birth, and fewer neonatal deaths [5]. Hence, side effects appear to be occurring more in women with poorer health literacy. Maternal health literacy is a skill to diagnose pregnancy risk symptoms. Having a healthy lifestyle and proper diet during pregnancy is a positive factor in the health of the mother [5]. Therefore, although it is essential to talk about the topics and give information regarding pregnancy, what is important is the level of understanding, awareness, and the ability to use this information in cases of necessity and risk. Therefore, there is a need for comprehensive efforts to increase maternal health literacy [6]. Before and during pregnancy, education on nutrition and counseling women of childbearing age can be an ideal opportunity for regulating the daily consumption of iron and folic acid by them. In the health education, theory predicts the consequences of programs, and provides a framework for educational intervention planning that helps us to analyze success or failure [7]. According to done studies, one of the most famous theories about how to predict and describe behaviors is the "Theory of Self-efficacy", which is used in behavior change. Bandura describes it as a person's judgment of his/her ability to act. It is clear when people believe capable of acting effectively, they are more likely to perform particular behavior. A person with low selfefficacy is less likely to try on new health behaviors or change the behavioral habits. In fact, a strong sense of self-efficacy is associated with health promotion [1]. Empirical evidence from studies also supports the relationship between self-efficacy and the establishment and maintenance of health behaviors. Therefore, it can be a used for promoting health, education, and adherence to various dietary regimens [1]. Self-efficacy theory cares about the role of self-confidence in performing desired behaviors. Perceived self-efficacy is an important predictor of the intent and ability to accept health patterns [8]. Moreover, self-efficacy is used as an essential component in health research and in the etiology of health and disease. Self-efficacy is known as an important predictor of behavior change in managing nutritional habits, smoking cessation and weight control. Selfefficacy is a basic structure of Bandura's social cognitive theory and reflects the individual's self-confidence in being able to adopt and perform a special behavior [9]. Therefore, the study and recognition of predictive variables of health in promoting healthy behaviors of women in childbearing age can be a step forward in improving maternal health and pregnancy outcomes [7]. Over the past few decades, healthy behaviors have been strongly promoted for healthy food, but the desire and ability to adopt a healthy lifestyle and change people's behavior towards these healthy behaviors is a complex issue [10]. The mother's diet is effective both on maternal and fetal health. Nutritional behaviors affect mother's weight gaining during pregnancy and having a healthy baby. Getting insufficient nutrition and supplements during pregnancy can result in inappropriate condition for fetus, such as low birth weight and delayed physical and mental growth. Understanding nutritional status and dietary self-efficacy can change the diet of pregnant women, which benefits the mother and the baby. Increased awareness of pregnant women, nutritional anemia can be reduced by having a healthy diet, and subsequently, preventing low birth weight [11]. Low skilled and low literate women began their pregnancy later, and their admittance was inadequate [12]. Prenatal care during pregnancy has reduced fetus mortality, low birth weight, and increased maternal weight gain during pregnancy [13]. Since identifying people with inadequate health literacy is very important and health care providers are often weak in this regard, identifying these people with low levels of health requires specific methods [14]. To increase the level of people's health literacy, using approaches such as 
streamlining information can be helpful. However, it has been shown that the use of communication strategies and getting assistance from health education professionals to plan and design useful and effective programs tailored to the target groups and their skill levels are efficient as well. They should choose the best educational approach to be able to make the best improvement in the level of health literacy that is a very important and vital issue [15].

Hence, health literacy is very important in mothers who play an important role in promoting the health of the whole community and family, and it has a direct impact on the performance or nonperformance of health behaviors,

This study aimed at investigating correlation between maternal health literacy and dietary self-efficacy in pregnant mothers.

\section{Instruments and Methods}

This is a cross-sectional descriptive-analytical study that it was conducted on 120 pregnant women who were covered by health centers in Mashhad City, Iran in 2016. The sample size was determined with a 95\% confidence interval and $80 \%$ test power, using the formula for estimating the mean of a quantitative variable. The subjects were selected through multi-stage cluster random sampling. To access the research samples, four clusters were randomly selected from the five health centers of Mashhad. Then, from each cluster, four health centers were selected randomly (a total of 16 health centers). Finally, by referring to the health centers and examination of the families cases, the pregnant mothers who had conditions for participation in the study were randomly selected., they were asked to refer to the health center to fill in the questionnaire by telephone. Entry criteria were mothers with a newborn and willing to participate in the study. The exit criteria included suffering from chronic illnesses, presence of high risk conditions during pregnancy, and lack of education in medical sciences.

Two questionnaires were used as a tool in this research:

MHLAPQ (Maternal health literacy and pregnancy outcomes questionnaire): MHLAPQ was used to collect the required

Health Education and Health Promotion data. In the demographic information section, such as questions about the age of the mother and the spouse, the level of mother and wife's education, the mother's and the spouse's job, and the level of family income, as well as information on pregnancy, including the first day of the last pregnancy (LMP), pregnancy age, current complaints, voluntarily or involuntarily pregnancy, laboratory information (hemoglobin level, weight, BMI), etc. were asked from each mother. MHLAPQ was used to measure maternal health literacy $[16,17]$. This questionnaire has 25 questions. Each mother answered to the questions with strongly agree, agree, disagree, and completely disagrees. Validity and reliability of MHLAPQ have been confirmed by Karazi et al. [17].

PDSEQ (Demographic questionnaire, perceived dietary self-efficacy questionnaire): Perceived PDSEQ was used to determine the level of self-efficacy of pregnant mothers [11]. The questionnaire consisted of 20 items including questions related to the quality of diet (10 items), supplementary diet (6 items) and prohibited diet ( 4 items). The quality of a diet is a normal balanced diet that is sufficient for adequate growth and proper nutrition in the fetus and the pregnant mother. Supplements include iron supplementation and folic acid. The prohibited diet is the food, which is harmful to the mother and the child. The Likert 5-point scale was used to answer the questions, and all 20 items were expressed as positive. The minimum and maximum scores were 20 and 100 in this questionnaire, respectively [11]. Cronbach's alpha coefficient was 0.89 in the health literacy questionnaire and 0.91 in the perceived dietary self-efficacy questionnaire. Repeat test results showed the stability of the questionnaire and subcategories. Duration of data collection was three months.

Mothers participated in the study after knowing the purpose of the study and completing the consent form. To observe ethical issues, coded, confidential, and unnamed questionnaires were used.

Data analysis was performed using SPSS 15 software and analytical tests. Independent ttest was used to examine the relationship between quantitative and qualitative variables, ANOVA and Tukey's tests for comparison of the means of more than two 
variables, and Pearson's correlation to determine the correlation of quantitative variables with each other at the $95 \%$ and $99 \%$ significance levels.

\section{Findings}

The mean age of mothers was $27.2 \pm 5.1$ years. The minimum age for mothers was 14 years and the maximum age was 42 years. The mean age of Husband was $31.7 \pm 5.8$ and the maximum age was 50 years.

$84.2 \%$ of their spouses were self-employed, $7.5 \%$ were unemployed and $8.3 \%$ were employees of government departments. In terms of economic indicators, only $22.2 \%$ of them had an income of higher than 10 million Rials, while others had lower incomes (table1).

Table1) Distribution of Absolute and relative frequency in the samples (120 people)

\begin{tabular}{lcc}
\hline Variable & Number & Percent \\
\hline Education & 30 & 25.0 \\
Elementary & 31 & 25.8 \\
Junior high school & 41 & 34.2 \\
High school diploma & 18 & 15.0 \\
College educated & & \\
Occupation & 116 & 96.7 \\
Housewife & 4 & 3.3 \\
Employed & & \\
Location & 65 & 54.2 \\
City & 55 & 45.8 \\
\hline Village & & \\
\hline
\end{tabular}

The average self-efficacy of mothers was $80.1 \pm 12.4$, with a minimum self-efficacy of 40 and a maximum of 100 . The average maternal health literacy rate was $42.5 \pm 7.6$ in MHLAPQ with a minimum of 21 and a maximum of 56 .
There was a positive and significant correlation between maternal health literacy and dietary self-efficacy $(\mathrm{r}=0.29 ; \mathrm{p}=0.001)$. Self-efficacy improves the health literacy of pregnant mothers.

However, there was no significant relationship between the mother's and spouse's age with maternal health literacy and dietary self-efficacy. There was no significant relationship between maternal health literacy $(p=0.42)$ and job, but there was a significant relationship with educational level $(\mathrm{p}<0.001)$, place of living $(p=0.001)$ and household income $(p=0.008)$.

There was difference between the average level of health literacy and the level of education in those who had university education compared to the rest of the groups. The average level of health literacy was higher in people with higher education than in other groups.

The mean of self-efficacy was $86.2 \pm 11.8$ in mothers with a monthly household income of more than 10 million Rials, and the difference was significant $(p \leq 0.05)$. The level of education, occupation and place of residence were not significantly correlated with dietary self-efficacy, but this difference was significant in the family's monthly income (Table 2).

Variables related to pregnancy such as the number of pregnancies, the number of alive children, the birth weight of the baby, the onset of care, the number of cares during pregnancy, the use of ferrous sulfate, the use of multivitamin supplementation and anemia

Table 2) Comparison of Statistical Averages of maternal health literacy and dietary self-efficacy with respect to demographic characteristics in the samples (120 people)

\begin{tabular}{lcccc}
\hline Variable & $\begin{array}{c}\text { Maternal health } \\
\text { literacy }\end{array}$ & Test statistic \& p-value & $\begin{array}{c}\text { Dietary self- } \\
\text { efficacy }\end{array}$ & Test statistic \& p-value \\
\hline Level of Education & & & & \\
Elementary & $38.9 \pm 8.1$ & $\mathrm{~F}=6.812$ & $77.3 \pm 13.0$ & $\mathrm{~F}=1.186$ \\
Junior high school & $42.6 \pm 6.3$ & $\mathrm{p}<0.001$ & $80.2 \pm 11.3$ & $\mathrm{P}=0.318$ \\
High school diploma & $42.4 \pm 7.0$ & & $48.1 \pm 14.9$ & \\
College educated & $48.4 \pm 6.6$ & & & \\
Occupation & & $\mathrm{t}=0.792$ & $46.5 \pm 6.6$ & $\mathrm{t}=0.071$ \\
Housewife & $42.5 \pm 7.4$ & $\mathrm{p}=0.43$ & $42.5 \pm 15.2$ & $\mathrm{p}=0.088$ \\
Employed & $39.5 \pm 12.5$ & & & $\mathrm{t}=0.958$ \\
Location & & $\mathrm{t}=4.387$ & $81.1 \pm 12.2$ & $\mathrm{p}=0.340$ \\
City & $45.0 \pm 6.2$ & $\mathrm{p}<0.001$ & $78.9 \pm 12.6$ & \\
Village & $39.4 \pm 8.0$ & & & $\mathrm{~W}$ \\
\hline
\end{tabular}


had significant statistical relationships with maternal health literacy $(\mathrm{p}<0.05)$, but there was no relationship with the history of abortion $(\mathrm{P}=0.924)$. In examining the difference between the average health literacy rate and the number of pregnancies, the number of alive children, the onset of care and the number of cares during pregnancy, this difference was related to those mothers who had more than three pregnancies, more, than two deliveries, more than three children, six times care or more and referred to the health centers in the second semester of pregnancy for the first time. The rest had no difference. Regarding the mean of dietary self-efficacy, there was a statistically significant relationship with supplemented ferrous sulfate $\quad(p=0.001), \quad$ multivitamin supplementation $(\mathrm{p}<0.001)$ and anemia $(p=0.007$; table 3$)$.

Table 3) Comparison of Statistical Averages of pregnancy-related variables with nutritional self-efficacy and maternal

\begin{tabular}{|c|c|c|c|c|c|}
\hline Variable & $\begin{array}{c}\text { Number } \\
\text { (Percent) }\end{array}$ & $\begin{array}{c}\text { Maternal health } \\
\text { literacy }\end{array}$ & $\begin{array}{c}\text { Test statistic \& } \\
\text { p-value }\end{array}$ & $\begin{array}{c}\text { Dietary } \\
\text { self-efficacy }\end{array}$ & $\begin{array}{c}\text { Test statistic \& p- } \\
\text { value }\end{array}$ \\
\hline \multicolumn{6}{|l|}{ Gravidity } \\
\hline 1 & $36(30)$ & $81.6 \pm 13.5$ & \multirow{3}{*}{$\begin{array}{l}F=0.440 \\
P=0.645\end{array}$} & $44.7 \pm 7.8$ & \multirow{3}{*}{$\begin{array}{l}F=3.442 \\
P=0.035\end{array}$} \\
\hline 2 & $48(40)$ & $70.0 \pm 12.7$ & & $42.4 \pm 7.7$ & \\
\hline$\geq 3$ & $36(30)$ & $80.1 \pm 10.8$ & & $40.1 \pm 6.6$ & \\
\hline \multicolumn{6}{|l|}{ Abortion history } \\
\hline Yes & $24(20)$ & $79.6 \pm 11.2$ & $\mathrm{t}=0.246$ & $42.6 \pm 5.9$ & \multirow{2}{*}{$\begin{array}{l}t=0.096 \\
p=0.924\end{array}$} \\
\hline No & $96(80)$ & $80.3 \pm 12.7$ & $\mathrm{p}=0.806$ & $42.4 \pm 7.9$ & \\
\hline \multicolumn{6}{|l|}{ Birth weight } \\
\hline$<2500 \mathrm{gr}$ & $6(5)$ & $78.0 \pm 7.9$ & $t=-0.433$ & $27.33 \pm 4.8$ & \multirow{2}{*}{$\begin{array}{l}t=-5.630 \\
p<0.001\end{array}$} \\
\hline$\geq 2500 \mathrm{gr}$ & $114(95)$ & $80.2 \pm 12.6$ & $p=0.666$ & $43.2 \pm 6.8$ & \\
\hline \multicolumn{6}{|c|}{ Number of live children } \\
\hline 1 & 44 (36.7) & $82.3 \pm 13.2$ & & $45.7 \pm 7.5$ & \multirow{3}{*}{$\begin{array}{l}F=4.901 \\
P=0.009\end{array}$} \\
\hline 2 & $47(39.1)$ & $77.3 \pm 12.5$ & $\begin{array}{l}F=2.183 \\
P=0.117\end{array}$ & $41.8 \pm 8.1$ & \\
\hline$\geq 3$ & $29(24.2)$ & $81.5 \pm 10.1$ & & $39.6 \pm 6.5$ & \\
\hline \multicolumn{6}{|c|}{ Beginning of prenatal care } \\
\hline First 3 semester & $74(61.7)$ & $80.7 \pm 12.3$ & \multirow{3}{*}{$\begin{array}{l}F=0.438 \\
P=0.646\end{array}$} & $44.9 \pm 6.9$ & \multirow{3}{*}{$\begin{array}{c}\mathrm{F}=12.543 \\
\mathrm{p}<0.001\end{array}$} \\
\hline second 3 semester & $41(34.1)$ & $78.8 \pm 12.6$ & & $38.4 \pm 7.1$ & \\
\hline Third 3 semester & $5(4.2)$ & $82.8 \pm 13.7$ & & $38.8 \pm 6 / 2$ & \\
\hline \multicolumn{6}{|c|}{ Multivitamin supplements } \\
\hline Yes & $84(70)$ & $83.0 \pm 11.0$ & $\mathrm{t}=4.171$ & $45.3 \pm 5.9$ & \multirow{2}{*}{$\begin{array}{l}t=7.630 \\
p<0.001\end{array}$} \\
\hline No & $36(30)$ & $73.4 \pm 12.9$ & $\mathrm{p}<0.001$ & $35.8 \pm 7.5$ & \\
\hline \multicolumn{6}{|c|}{ Number of cares during pregnancy } \\
\hline$<5$ & $25(20.8)$ & $36.6 \pm 7.5$ & \multirow{3}{*}{$\begin{array}{l}F=1.337 \\
P=0.267\end{array}$} & $36.6 \pm 7.5$ & \multirow{3}{*}{$\begin{array}{c}\mathrm{F}=15.920 \\
\mathrm{p}<0.001\end{array}$} \\
\hline 5 & $21(17.5)$ & $40.3 \pm 5.5$ & & $40.3 \pm 5.5$ & \\
\hline$\geq 6$ & $74(61.7)$ & $45.0 \pm 6.8$ & & $45.0 \pm 6.8$ & \\
\hline \multicolumn{6}{|c|}{ Ferrous sulfate supplementation } \\
\hline Yes & $90(75)$ & $82.3 \pm 11.3$ & $\mathrm{t}=3.515$ & $44.5 \pm 6.1$ & $\mathrm{t}=5.843$ \\
\hline No & $30(25)$ & $73.6 \pm 13.4$ & $\mathrm{p}<0.001$ & $36.3 \pm 8.1$ & $\mathrm{p}<0.001$ \\
\hline
\end{tabular}

\section{Discussion}

In the present study, considering the relationship of health literacy and self-efficacy with demographic characteristics, based on the results of Spearman's correlation coefficients, there was no significant relationship between the mother's and father's age, maternal health literacy and dietary self-efficacy. According to the results of the one-way ANOVA and independent sample t-test, there was no significant relationship between maternal education and maternal health literacy. There was a difference regarding the people with university education. However, there was no significant relationship with dietary selfefficacy. Maternal occupation had just a significant relationship with maternal health literacy. Family monthly income showed a significant relationship with all the variables.

The place of living had a significant relationship with maternal health literacy but not correlated with dietary self-efficacy.

In the study of Javadzadeh et al. entitled "Adult Health Literacy in Isfahan", there was a significant relationship between health 
literacy level and age, educational level, gender and economic status, so that inadequate health literacy was observed in older people with less education, women and the low income group [18]. In his study titled "Health awareness and health status in type 2 diabetic women referring to hospitals affiliated to Tehran University of Medical Sciences, Tal associated health literacy with job and education level [19]. Nekoubi Moghaddam et al. found a relationship between education level and health literacy [20]. Koshyar et al. expressed a reversal meaningful relationship between health literacy and age and a direct and significant relationship with family income. Also health literacy had a meaningful relationship with the level of education and occupation [21]. Amir Esmaili et al., in his study entitled "Health literacy level of pregnant women referring to health centers", indicated that health literacy had a significant relationship with age, education, abortion and number of children [22]. Reissi et al. also related health literacy to age, education level and household income [23]. Anderson found a relationship between health literacy and social-economic status of mothers. It had an impact on the care of the baby's life and health [24]. The target population of the above study included pregnant women with gestational diabetes, which was different from the present study. The majority of the mothers of our study had a weak economic level, which is probably due to the high cost of services in the private sector. This finding confirms the studies of Amir Ismaili [22] and Bakhshi [25]. Perhaps the reasons for the lack of consistency of the outcome of this study with some other similar studies could be the discrepancy between the measurement tools, the method of implementation, the interview, the target group, and the time and place of the study. In the present study, there was a significant difference between health literacy and living place. Other studies also showed this significant difference among the patients referring to the health centers of the city and villages and emergency centers [12, 26-29]. Family monthly income also had a meaningful relationship with health literacy, which is consistent with the study of Tall et al. [19], but Nekoi Moghadam et al.'s study did not show this relationship [22]. The high level of health literacy and knowledge in people with higher educational level confirms the role of education in this regard [2]. The findings of this study confirm this, and show that mothers with university education had significantly higher health literacy than other groups; other studies have achieved similar results [12, 24, 3033]; however, it is not consistent with the results by Kohan et al. [9]. Education is recognized as an important factor in health literacy. In order to minimize the impact of various factors including education affecting health literacy, a health system should be designed for people with low levels of literacy using simple illustrations and cultural examples through the media. Establishing simple communication and easy instructions can raise the understanding of health information [34]. In some studies in other parts of the world, there was no significant correlation between age and level of health literacy [35-37], which is confirmed by the results of this study. It is worth noting that regardless of the effect of different factors on health literacy and the effect of some of them, in particular education, on the other variables, housewives living in rural areas, with weak or impoverished economies, are subject to the consequences of having low health literacy. In approaching this group, people should use appropriate and reliable educational methods [12]. In the study of the relationship between maternal health literacy and self-efficacy in pregnant women referring to health centers, there was a positive and significant relationship between maternal health literacy and dietary self-efficacy based on Pearson's correlation coefficient. As a result, self-efficacy improves the health literacy of pregnant mothers. However, there was no significant relationship between the mother's and father's age with maternal health literacy and dietary self-efficacy. Ellen et al. (2006), in a cross-sectional study of 124 mothers in Los Angeles in 2014, found that mothers' selfefficacy was effective in protecting the health of mothers and their children [38]. In line with this study, Peyman et al., in the study titled "The relationship between health literacy and self-efficacy in postpartum women," introduced health literacy as an effective factor in self-efficacy. In this cross-sectional descriptive-analytical study, 120 mothers, aged 20 to 35 years, with a child less than 
three months were randomly selected from the health centers in Mashhad. The data collection tool was a physical self-efficacy questionnaire, a quick adult health literacy questionnaire, and Tafla Health Literacy Questionnaire. The results indicated that the average level of health literacy was $51.4 \pm 12.3 \%$. $27.5 \%$ had good health literacy, $42.2 \%$ had borderline health literacy, and $30 \%$ had unfavorable health literacy. Mean score of physical self-efficacy of the participating women was $84.3 \pm 41.4$. Also $18.3 \%$ of participants had a high self-efficacy, $47.5 \%$ had a moderate self-efficacy, and $34.2 \%$ had a low self-efficacy. There was a significant relationship between health literacy, and female self-efficacy. Women with adequate health literacy were significantly more self-efficacious [39]. The reason for the uncertainty of some results can be the difference in the measurement tools in both health literacy and self-efficacy variables as well as the difference in location. In the study of Dumming et al., high health literacy scores predicted changes in self-efficacy [40]. Also, in Raisi et al.'s study, functional health literacy was the most important predictor of selfefficacy of diabetic patients for self-care behaviors [41]. Oziren et al. showed that there was a significant relationship between health literacy, self-efficacy and physical activity [42]. Prenatal care is the proper implementation of the principles that are aimed at maintaining the health of the mother and the birth of a healthy baby [43].

Non-printed media are the only effective ways to deliver a health message to those who have little practical literacy. These media may include images and radio tapes. Even readily readable patients prefer non-written materials such as illustrated books, videotapes, audio tapes, or multimedia presentations. In order to increase the level of people's health literacy, using approaches such as streamlining information can be helpful, but experience has shown that besides these, the use of communication strategies and getting assistance from health education professionals to plan and design useful and effective programs tailored to the target groups and their skill levels are effective. The practitioners should choose the best educational approach to be able to make the best improvement in the level of health literacy that is a very important and vital issue. They should improve this ability among different social classes. Therefore, although it is essential to educate and provide information in pregnancy, what is important is the level of understanding, awareness, and the ability to use this information in cases of necessity and risk. Therefore, there is a need for comprehensive efforts to increase maternal health literacy. Practical interventions to improve health literacy, such as clear communication with mothers, use of intelligible and illustrated media, visual teaching aids, and creation of an enabling environment for questioning, can improve it. Given the working hours of health centers, mothers or students had less chance of participating in this study. Given that the present study is a cross-sectional study, it was not possible to achieve causal relationships. Among other constraints of the study, selfchecking was the tool of study, which was eliminated by the questioner.

\section{Conclusion}

There are the significant correlation between maternal health literacy and self-efficacy in pregnant mothers.

Acknowledgment: The present study was the result of a Master's degree thesis in health education and health promotion at Mashhad School of Public Health, Mashhad, Iran (project No. 922890, dated 17/10/1393), approved by the Deputy of Research and Technology of Mashhad University of Medical Sciences. We thank the Vice-Chancellor for Research in Mashhad University of Medical Sciences and all the participants in this study.

Conflicts of interests: Non-declared

Ethical permissions: This research was approved by IRCT: IRCT2017062928863N18 code.

Authors' Contribution: Authors' contribution has not been reported separately.

Funding/ Support: The financial sources of this study have been provided by Mashhad University of Medical Sciences.

\section{References}

1- Gaur RC. Environmental engineering laboratory manual for first year engineering students. $1^{\text {st }}$ edition. 
New Delhi: New Age International Ltd Publishers; 2007. 2- Mouli PC, Mohan SV, Reddy SJ. Electrochemical processes for the remediation of wastewater and contaminated soil: Emerging technology. J Sci Ind Res. 2004;63:11-9.

3- Patel UD, Suresh S. Electrochemical treatment of pentachlorophenol in water and pulp bleaching effluent. Sep Purif Technol. 2008;61(2):115-22.

4- Chen G, Electrochemical technologies in wastewater treatment separation. Sep Purif Technol. 2004;38(1):1141.

5- Addy SE, Gadgil AJ, Kowolik K, Kostecki R. Electrochemical removal (ECAR) for rural Bangladeshmerging technology with sustainable implementation. Berkeley: Lawrence Berkeley National Laboratory;2009. 6- Ni'am MF, Othman F, Sohaili J, Fauzia Z. Removal of cod and turbidity to improve wastewater quality using electrocoagulantion technique. Malays J Anal Sci. 2007:11(1);198-205.

7- Khanniche MS, Morgan PG, Khanniche KN, Jobling CP, Khanniche N. A novel electro-chemical process for water treatment. Rev Energ Ren. 2001:63-7.

8- Mesdaghinia AR, Rabbani D, Nasseri S, Vaezi F. Effect of coagulants on electrochemical process for phosphoruremoval from activated sludge effluent. Iran J Publ Health. 2003;32(4):45-51. [Persian]

9- Ramirez N, Regueiro A, Arias O, Contreras R. Electrochemical impedance spectroscopy: An effective tool for a fast microbiological diagnosis. Biotecnol Apl
2009;26:72-8.

10- Szynkarczuk J, kan J, Hassan AT, Donini JC. Electrochemical coagulation of clay suspensions. Clays Clay Miner.1994;42(6):667-73.

11- Mostafapoor F, Bazrafshan E, Kamani H. Effectiveness of three coagulants of polyaluminum chloride, aluminum sulfate and ferric chloride in turbidity removal from drinking water. Zahedan J ResMEd Sci.2008; 10(2):17-25. [Persian]

11- Merzouka B, Gourichb B, Sekkic A, Madanid K, Chibaned M. Removal turbidity and separation of heavy metals using electrocoagulation-electroflotation technique: A case study. J Hazard Mater. 2009;164(1):215-22.

12- Rajkumar D, Palanivelu K, Electrochemical treatment of industrial wastewater. J Hazard Mater. 2004;113(13):123-9.

13- Abuzaid NS, Bukhari AA, Al-hamouz ZM. Ground water coagulation using soluble stainless steel electrodes. Adv Environ Res. 2002;6(3):325-33.

14- Lai CL, Lin SH. Treatment of chemical mechanical polishing wastewater by electro coagulation: System performances and sludge settling characteristics. Chemosphere. 2004,54(3):235-42.

15- Venkitanarayanan KS, Ezeike GO, Hung YC, Doyle MP. Efficacy of electrolyzed oxidizing water for inactivating Escherichia coli 0157:H7, Salmonella enteritidis, and Listeria monocytogenes. Appl Environ Microbiol. 1999;65(9):4276-9. 